\title{
Staying Employed and Employing Others: Leadership Styles and Management Strategies of Proprietors of Micro Enterprises in Developing Countries
}

\author{
P. АКРАMAH \\ University of Cape Coast, Ghana, akpamah.peter@yahoo.com
}

\begin{abstract}
This study sought to find out the leadership style and management strategies of the proprietors of micro enterprises that have enabled them to stay in business this long and offering employment to several others in the midst of unfavourable economic conditions in developing countries. Management strategy and leadership style are complementary in pursuing organizational goal. Though, literature on the subject reveals that not much research has been done on the survival of micro business on the African's continent regarding owners' management strategies and the leadership style. We used mix methods in data collection and purposive samplings of thirty (30) micro enterprises' proprietors were interviewed. The result reveals that owners of micro business practice multistrategies in their organizations. The Study found out that the Laissez Faire or Free Rein Leadership and the Bureaucratic Leadership were not practiced by any of the research participants. However, Authoritarian Leadership with strict instructions dominated Democratic Leadership and appeared to have been very effective and yielded result in most micro businesses.
\end{abstract}

Keywords: management strategies, leadership style, micro business.

\section{Introduction}

Business mortality rates all over the world are very high [1]-[2]. Many are the ventures that do not survive beyond a few months after their establishment, throwing their founders and so many others into unemployment [3]. Even in developing economies, many businesses, both large and small are said to fail with the first one to two years of establishment [4]. Many countries do ignored the need to develop strategies to support industrialization and technologies among small and medium-sized enterprises to increase productivity and employment for the youth [1]. Recent empirical experience in effective enterprise development and growth of existing organizations demonstrates the failure of businesses to use integrated and holistic approach to match demand with local resource potentials for substantial and efficient employment opportunities [5]. The situations is far worse in developing countries due to among many other reasons, the non-functional nature or complete absence of supporting institutions to promote the development of businesses, a situation referred to as institutional voids [6]. This has led to a situation where the private sector, the engine of growth and development and source of employment is teetering at the brink of collapse [7]. 
The fight against unemployment requires accurate information on the characteristics and strategies of enterprises; large or small, young or mature, operating in modern or traditional industries where new jobs can possibly be generated [8]. The micro-businesses play a very important role in employment generation in any developing country, but have received very little experiential attention regarding managerial competence, strategies and efficiency [4]. Despite this gloomy situation however, there are individuals operating micro enterprises that have existed for long, employing themselves and keeping other people employed as well. Out of the $86 \%$ of small firms in Ghana duly registered with the relevant local authority, 92\% of these businesses are owned and managed by a single individual with about $75 \%$ of stable employment [9]. These persons or groups of individuals have defied all odds to start and operate businesses that have employed themselves and others in the past years. The aim of this research is to find out the leadership style and management strategies of owners of these micro enterprises that have enabled them to stay in business this long, that is remaining employed and even offering employment to several others in the midst of unfavourable economic conditions in developing countries.

\section{Theoretical Background}

The term strategic management was first used in the 1950s and became renowned between the mid1960s and the mid-1970s as it was considered the panacea to all challenges in the business environment [10]. Though, the strategic management was seen obsolete in 1980s when various planning models were introduced [10]. However, the practice of strategic planning in organizations became prominent since the 1990s [4]. Strategic management and planning are seen the same in some jurisdictions [11]. Strategic planning is simply the foundation for planning in any enterprise [12] whereas strategic management is the art of formulating policies, implementing growth strategies and assessing various decisions to ensure that organizational objectives are achieved [10]. A growth strategy is a deliberate action of organization to scale up production [13].

In organizations, the annual plans and long-range plans look at the company's current businesses and its existence growth strategies [14] whereas strategic plan deals with how to take advantage of opportunities in the firm's challenging environment [12]. Strategic planning turns organization's vision and mission into reality [10]. The strategic analysis deals with the setting up of the organization's vision, mission and goals which includes working towards the firm's strategic intent and directing efforts on understanding the business environment [11]. Strategic choice generates, assesses and selects the precise strategy for the firm [14] whereas strategy implementation positions the relevant policies and structures to facilitate the effectiveness and efficiency of the entire strategic planning [15]. Effective strategy implementation greatly depends on a mixture of factors [16].

Social networking is one of the 21st century business strategies for knowledge, new opportunities and best practices [13]. Networking enables access to growth opportunities, emotional support and teamwork with other industries [17]. Personal motivation couple with innovative skill and positive attitude towards customers and commitment to work present a growth strategy of micro-businesses [18] - [19]. The nature of a business, management attitude together with the business objectives and leadership style often determine growth strategy in micro enterprises [13]. The presence of cordial 
relationship within and beyond organizational setting is prime determinant of growth strategy in a given organization [14]. Business located at a vantage point among unrelated group of businesses to attract customers of the existing businesses is regarded as growth strategy [20]. A growth strategy is assessed by the number of consumers attended to and the quantity of goods and service produced within the stipulated period [17]. Micro-businesses stand a high risk of taking advantage of producing new product as a result of innovation and pursuit of customers [17]. The desire to be innovative should not only be responding to customer demands, rather to remain employed by inventing and developing new product and service that were previously not envisaged [21]. The business owners influence performance and growth in firms through different strategic entrepreneurial orientation guided by their valued priorities [22]. Strategy growth consultation and implementation is not exclusive to only medium and large size organizations, but many a proprietor of micro businesses consults both industries and individuals at the implementation stage [10].

Globalization has weakened industrial boundaries enabling sole proprietorship to adopt new opportunities in which micro-businesses today are in production that were not of their origin [23]. Besides, computerization compels management to encourage consumer's participation in firms' decision and strategies design [24]. The sole proprietorship, popularly known as the one-man business is the oldest and commonest type of business unit in both developed and developing countries [25]. The one-man business is a type of business organization in which an individual controls production and bears all risks of the production [26]. This type of business requires small investment and individual leadership style [25].

Leadership to a large extend is culturally orientated, embraced traditional beliefs, preoccupation, and norms and values [27]. The 21st Century Leadership is characterised by cycle of globalisation and the changing landscape of jobs in global value chains which requires distinct micro enterprises to develop integrated approach to growth so as to maximise employment opportunities [23]. Leadership has the characteristics of individual influence, spiritual encouragement and intellectual stimulation [28]. The character, preferences, strategic planning and leadership style of organizational leaders have obvious reflective influence on their enterprises [29]. Flexible training, education and employment services are compulsory for business owners to bridge the gaps between leadership style and business strategy [23]. The survival or failure of organizations has largely been credited to the nature and the relationship between leadership style and management strategies [30]. The characteristics of a leader have direct effect on the employees and organizational citizenship behaviour which further enhances the relationship between leadership style and organizational commitment [31]. A leadership that concentrates on the growth and development of value system of employees, their inspirational level and moralities with reference to their abilities can easily lead to the development of workers, their needs and poverty alleviation [32].

Management style and leadership style are generally comprised the attitudes and behaviours of managers [33]. Management style and leadership style are different in theory, but the same in daily business practice [11]. Management style is often associated with the characteristics of the leader [34]. The type of leadership style is significantly influenced by environment and culture [35], and the relationship between organizational leadership and business growth has ethical influence on the 
organization and the wider community [36]. Leadership styles in organizations are practiced differently by entrepreneurs to overcome institutional challenges [37]. Decisions are often made easily in a firm managed by individuals as a result of its autonomy [38]. Most private firms perceived to practicing participative style, but they are more into autocratic leadership style [35]. Transactional leadership signs contract on performance between leadership and employee, that is a reward to employee for meeting organization's target [39] whereas transformational leadership style focuses on the intellectual development of the employee that translates into organizational growth and development [40]-[41].

\section{Conceptual Model}

A conceptual model in Figure 1 represents a significant relationship among management strategies, leadership style and employment opportunities in micro enterprises in developing economies. The type of management strategy adopted in organization has influence on the chosen leadership style just as the leadership style of a proprietor can often be traced to management strategy. This explains the fact that proprietors of micro businesses remained employed and create employment opportunities for others basically depends on their management strategies and leadership styles.

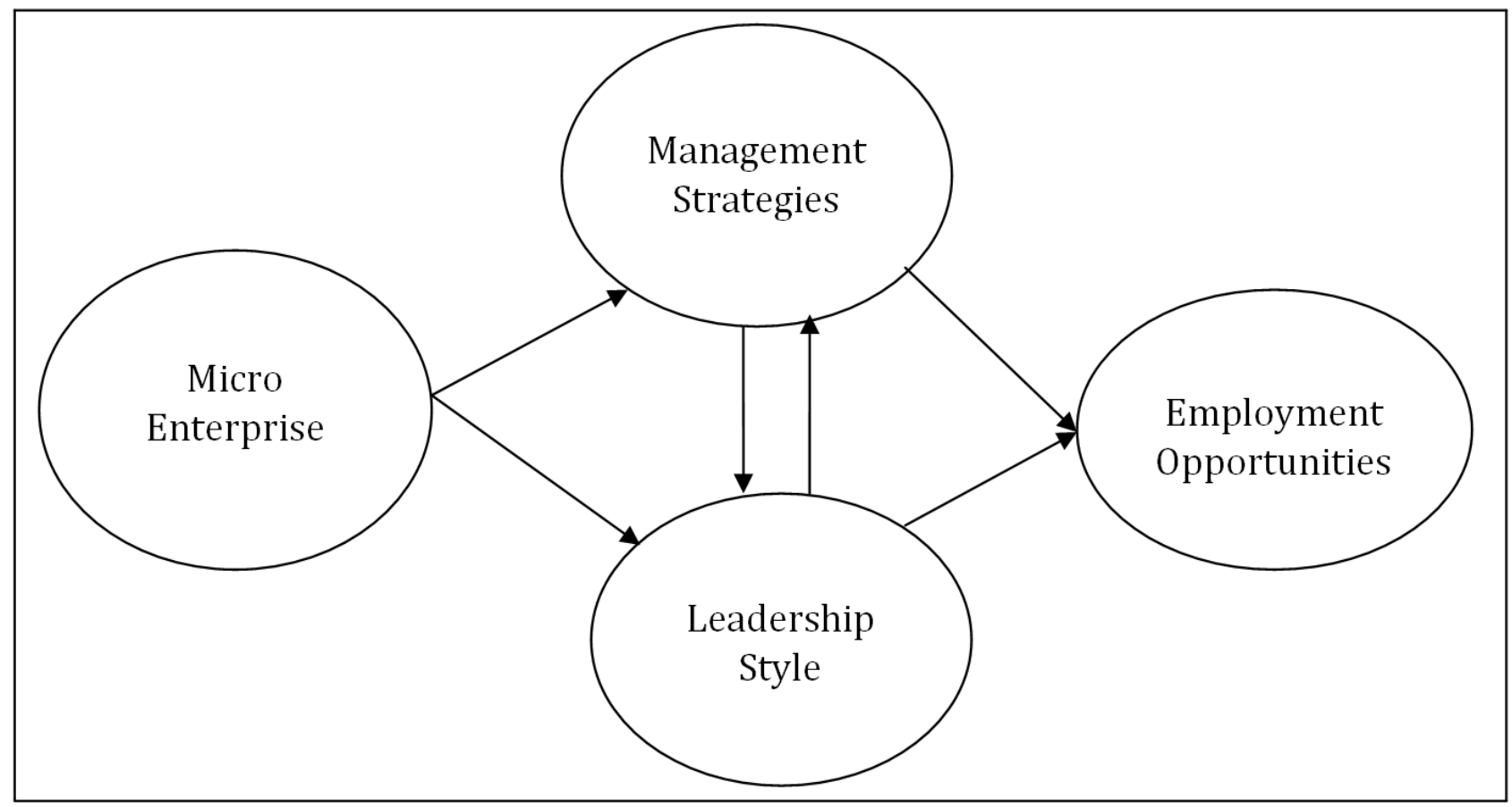

Figure 1: Research Model

Source: Own Source.

\section{Methodology}

Data were collected by mix methods. With the qualitative research method through in-depth interviews [42], we looked at the management strategies and leadership styles of proprietors of micro enterprises that have enabled them weather the storms of institutional voids and other ills that are inimical to business growth and development. There was also an extensive literature review of 
previous studies for secondary data to enable empirical investigation. The research was conducted on proprietors of micro enterprises in Bolgatanga, the Upper East Regional capital. Purposive samplings of thirty (30) micro enterprises' proprietors were interviewed. The questionnaire was adopted from a study "A Qualitative Study of the Growth Strategies of Mature Small Businesses" [17] and modified to suit the purpose of the study. To ensure reliability of the instrument, a pilot study was carried out to pre-test the instrument.

\section{Results Analysis and Discussions}

After data collection, a thorough check was done on the questionnaires proceeding coding and entering into software version 22.0 of the Statistical Package for Social Sciences (SPSS). Microsoft Excel, among others were used for the analysis of data and with broad description of the findings presented through percentages, frequencies, mean and standard deviation.

\section{Personal Characteristics}

The finding first deals with the composition of respondents. On Table 1, response on sex distribution demonstrates male respondents' dominance by $60 \%$ and the respondents' age bracket ranges between 26 and 35 years with the mean age of 17.70 and standard deviation 8.994 on Table 2 . The result suggests majority of micro businesses in developing countries are men in their active ages.

\begin{tabular}{|l|c|c|}
\hline Sex & Frequency & Percentage \\
\hline Male & 18 & 60 \\
\hline Female & 12 & 40 \\
\hline Total & $\mathbf{3 0}$ & $\mathbf{1 0 0}$ \\
\hline
\end{tabular}

Table 1: Sex of Respondents

Source: Fieldwork September, 2019.

Age is a possible determinant of growth strategies as far as knowledge through innovation is concerned [14]. The age bracket of the participants, therefore, might be among other reasons for their long stay in business. Many of these young men and women are married with household size of four or five persons as over $66 \%$ of the respondents reported married with $30 \%$ being single and less than $4 \%$ divorced as shown on Figure 2.

\begin{tabular}{|l|c|c|c|c|}
\hline Age Grouping & Frequency & Percentage & Mean & Std. Deviation \\
\hline 18 - 25 years & 7 & 23.3 & 12.71 & 8.731 \\
\hline $26-35$ years & 10 & 33.3 & 17.7 & 8.994 \\
\hline $36-45$ years & 6 & 20 & 17.83 & 8.976 \\
\hline 46 or more years & 7 & 23.3 & 13.14 & 8.989 \\
\hline Total & $\mathbf{3 0}$ & $\mathbf{1 0 0}$ & \\
\hline \multicolumn{5}{|c|}{ Table 2: Age Grouping of Respondents } \\
\\
Source: Fieldwork September, 2019.
\end{tabular}

The data in Figure 2 show a $63.3 \%$ of respondents living in households with members ranging between 4 and 5 persons whereas $3.3 \%$ of participants stay in households with members beyond 5 
persons. This explains why there is exponential increase in population growth and poor savings in third world countries [43].

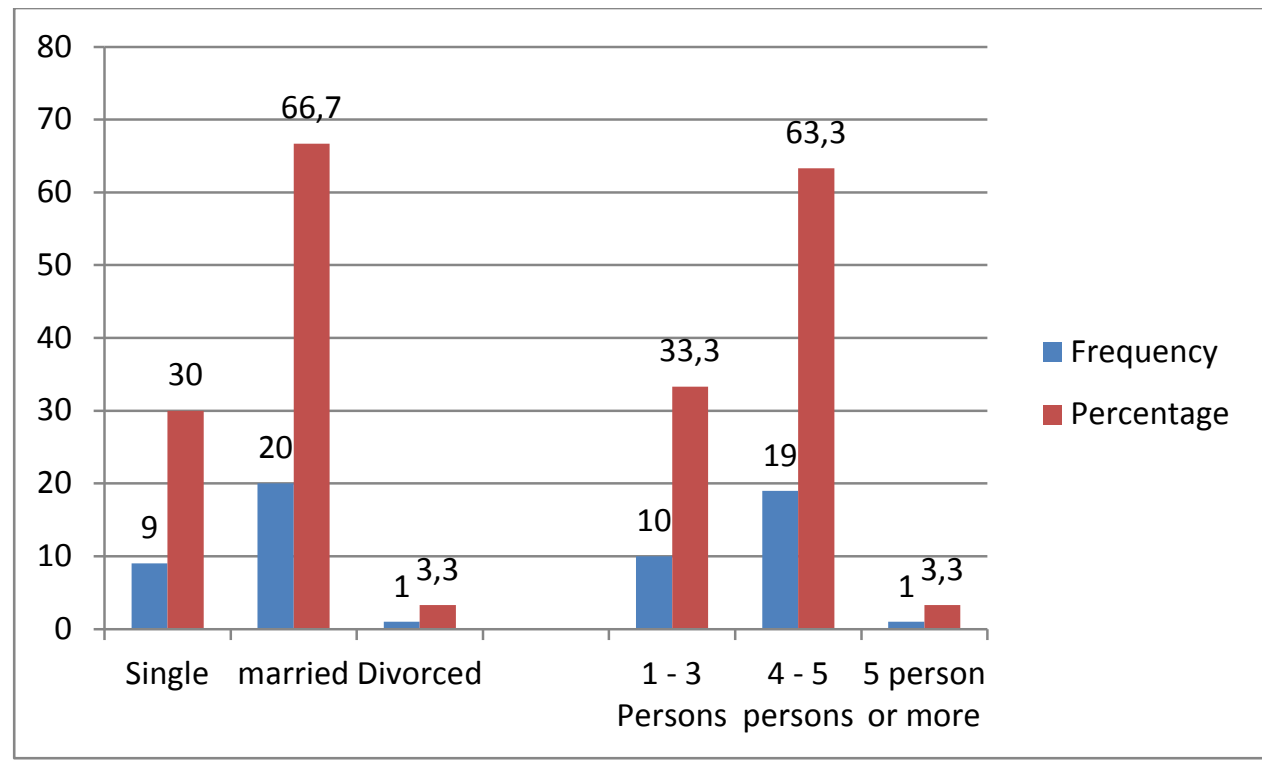

Figure 2: Marital Status and Household members of Respondents Source: Fieldwork September, 2019.

Majority of respondents are Basic Education Certificate (BEC) holders representing 36.7\% whereas those that attained secondary and tertiary education represent $20 \%$ each. The remaining percent, however, represents participants with no formal education as established data shown in Figure 3. This implies the standard of education in less developed countries has still not been in good shape. Then, the result confirms the statement that education system should not be despondency in whatever approach to education in any given nation [44].

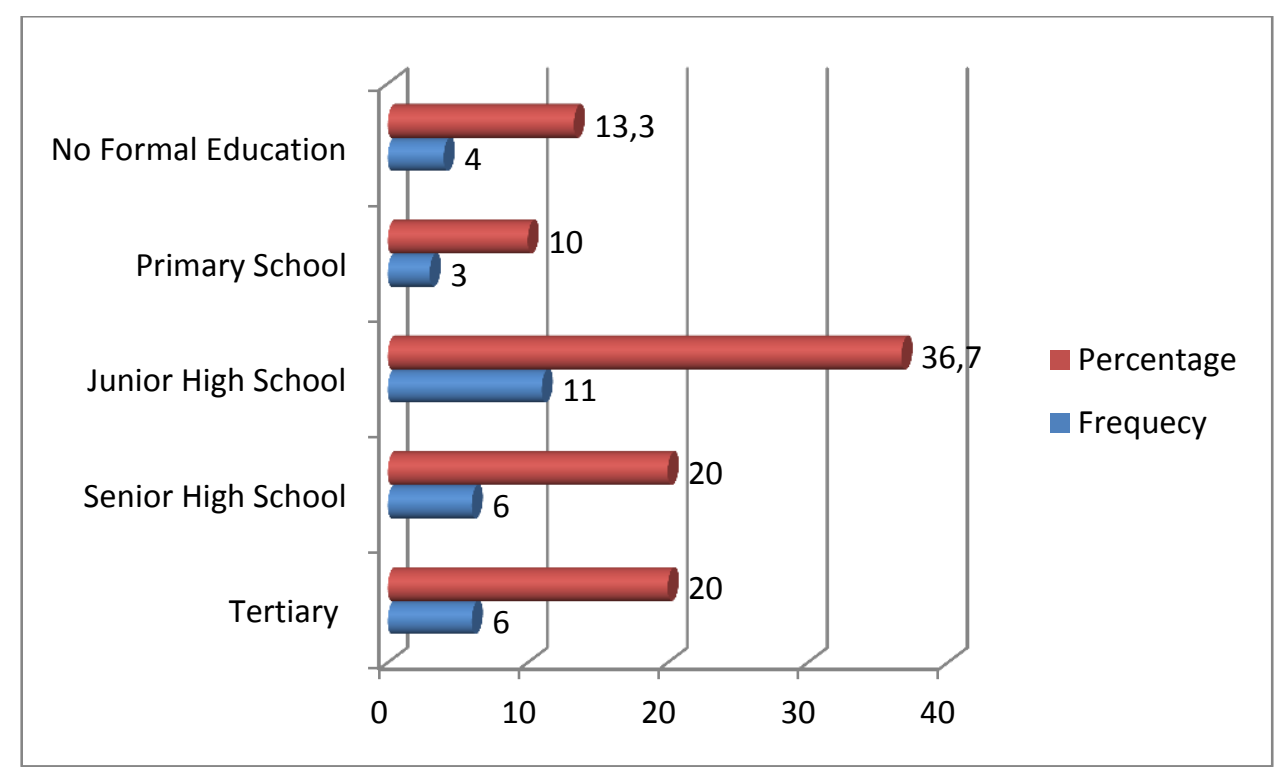

Figure 3: Educational Level of Respondents Source: Fieldwork September, 2019. 


\section{Business Characteristics}

Proprietors of micro-enterprises operating in urban and rural areas were both interviewed. The finding reveals $56.7 \%$ of respondents had their businesses located in urban communities and the remaining percent were found among the rural settlement. The result is a manifestation of the flooding of all kinds of businesses in the street of towns and cities in Africa. The laws governing the trade industry in Ghana need to be reinforced since a significant number of micro businesses operate in towns and cities, and less than $30 \%$ of respondents had their businesses registered with the appropriate authority as compared. This is contrary to a report in which small scale firms in Ghana duly registered with the relevant local authority had reasonable number of businesses owned and managed by single individuals [9]. The study reveals that Motor-Vehicle Mechanic/welder and Designer/Hair-dresser/barber were the most engaged jobs by the people at the time of the study as they recorded 30\% each proceeded by Leather works/Weavers/Blacksmith representing $23.3 \%$ with the remaining percent going to Mason/carpentry.

About $36.7 \%$ of respondents had their businesses in existence for less than ten years, but not less than six years followed by start-up businesses in their first to fifth year of existence recorded $26.7 \%$ whereas only $10 \%$ for enterprises survived for twenty-one years and beyond. Some of these enterprises either employed or worked with 4-6 persons representing $46.7 \%$ in which $73.3 \%$ were hired labour with their ages ranging between 18 and 25 years indicating 80\%. Besides, a lot of employees of these micro enterprises were Junior High School drop-outs equally demonstrating $80 \%$ with only $3.3 \%$ of tertiary institution graduates employed. The calibre of employees at the micro businesses should be a worry to a country that has her youth at heart. The result, therefore, shows the need to emphasize on the fact that education system should be designed such that the child as an individual gets to know much about himself or herself and his or her approach to learning [44].

Micro Enterprises that trained not less than three individuals in every three years also represents $80 \%$ with $16.7 \%$ of organizations trained within 6-10 persons in every three years. There is a continuation of employment and job creation opportunities when apprentices are given quality training under proper mentoring and supervision [45]. Though, with the advent of Non-Governmental Organizations and series of training, the unemployment in developing countries still remains a challenge. The economic growth in most third world countries is a worrying issue and needs to be tackled as the result points to only $20 \%$ of these enterprises are into manufacturing with the rest operating in the service sector. Besides, the products of these enterprises are locally consumed and worse of it, only $26.7 \%$ of the proprietors earned beyond One Thousand Ghana Cedi (GH\$ 1000.00) monthly contributing to the reasons that micro enterprises in less developed countries constantly break-even [4].

\section{Management Strategies of Micro Enterprises}

The study reveals that close to $90 \%$ of micro enterprises determined growth strategies by the sales and the revenue accrued to the business. The result shows that $16.7 \%$ and $3.3 \%$ of respondents assess growth strategies by the ability of the business to increase output and the number of trainees 
respectively. The result is in agreement with [17] position that growth strategy assessment associates with improvement of quantum of commodity sold. The finding validates [16] study that effective strategy implementation combines both internal and external factors. Customers' Relation Strategy was identified the most used with $40 \%$ of respondents affirmation followed by $23.3 \%$ for advertisement/marketing strategy. Innovative strategy recorded $20 \%$ whereas quality product/pricing strategy was used by only $16.7 \%$ of the respondents. The study confirms [18]-[19] findings that innovative skill and positive manner towards customers and commitment to work present a growth strategy of micro-businesses. The study points out that $40 \%$ of respondents had growth opportunities through consultation with family and friends while $30 \%$ of the respondents' identified growth with customers' request, however, $23.3 \%$ and $6.7 \%$ recognized growth opportunities through internet search and research respectively.

A peaceful co-existence within and beyond organization's settings brings about growth opportunity [14]. About $60 \%$ of respondents consult friends and relatives in the process of the development and implementation of growth strategy with only $6.7 \%$ respondents consult expert when developing and implementing growth strategies. The remaining 33.3\% goes to customer consult and testing market with new product. The finding supports a survey which states that consultation with both industries and individuals at the implementation stage is relevant in the trade industry [10]. Majority of respondents implement growth strategies with financial aid from relatives representing $70 \%$ whereas $10 \%$ take loans in order to put into operation growth strategies. Government and other external support to proprietors of micro enterprises to assist in the implementation of growth strategies made up of $20 \%$. Strategy implementation requires positioning of the relevant policies, experts and structures to guarantee efficiency [15]. The respondents outlined; financial challenges, high cost of raw material, traditional method, obsolete tools and equipment used in production as the main problems that they are confronted with in the implementation of their management strategies. They also mentioned high taxes and electricity bills without corresponding market coupled with structural flaw as a serious challenge.

\section{Leadership in Micro Enterprises in Developing Economies}

With the determination of leadership style in micro businesses, $36.7 \%$ of respondents think that the nature of business determines the type of leadership style to adopt whereas $60 \%$ responded positively to strategy plan and business objectives or goals as catalyst for choosing a leadership style, but 3.3\% of respondents considered workers attitude before they could settle on a particular leadership style. The result shows that not less than $53.3 \%$ of the micro business proprietors deployed autocratic leadership style in the running of their businesses. The result goes with the finding that decisions are often made easy in firms that are autonomy in nature [38]. Respondents acknowledge the use of democratic leadership style with a representation of $26.7 \%$ whereas $20 \%$ of respondents practice transactional leadership style.

The response confirms [37] study which states that adopted leadership styles in organizations are often varied and based on the nature and objective of the business so as to overcome institutional challenges. In micro businesses, $56.7 \%$ of respondents use laid down rules and regulations as well as 
strict instructions to implement a chosen leadership style. The discussion of business objectives and strategy plan/ skill development with employees as a means of implementing a leadership style in micro businesses was represented by $26.7 \%$ and $16.7 \%$ respectively. The study agrees with [23] findings that flexible training and educating the employees on strategy plan are compulsory for business owners to bridge the gaps between leadership style and a successful implementation of a business strategy.

When participants were questioned about the problem they face in implementing their leadership styles, they specified employees' failure to abide by strict instructions and the difficulty of employees to understand business objectives, even upon a thorough explanation.

The question on what respondents think would help build knowledge on the topic to strengthening micro businesses in Africa, over 70\% of respondents called for government support in the form of easy access to loans, in-service training, organized workshops and subside tools and equipment to enable the micro business operate effectively so as to remain in business and employ others. The remaining percent advocates for government policy on the exportation of locally produced goods and services as a means of opening market and transforming businesses in deprived regions. The provision of warehouses and storage facilities to keep raw materials and finished goods was one of the major concerns of the research participants.

\section{Conclusion}

We found out that with the autocratic leadership, the employer uses hard boiled or strict autocrat where no compliance of orders result in punishment or the benevolent autocrat where positive influence, effective human relations, praises of the employees as they take up instruction and accept solution to a problem from the leader or the manipulative autocrat where the leader creates in the minds of employees that they are participating in decision making, but makes decision all by himself/herself [37]. Respondents claimed that these characteristics and with various management strategies, the micro businesses have been able to withstand the unfavourable conditions. However, micro businesses in the study area do not often grow in size, and there is the need for further investigation to establish the negative effects of authoritarian leadership among the micro businesses in Africa.

\section{References}

[1] J., P. Grierson, Training for Self-employment in Somaliland: Project Proposal. Report to the Somaliland War Veteran's Association and Swiss Group, Somaliland, 1997. SKAT

[2] Y. Ling, \& L., Hong, How intellectual capital management affects organizational performance: using intellectual capital as the mediating variable. Taiwan Human Resource Management Student Newspaper, 2010, 10(1): 1-27.

[3] R., Caroline Micro and small enterprises as drivers for job creation and decent work. Discussion Paper / Deutsches Institut für Entwicklungspolitik, 2015, ISSN 1860-0441. 
[4] N., I. Akeke and Oladele O., P., Strategic Leadership Factor in Small and Medium Enterprises in Southwest Nigeria. International Journal of Economics, Commerce and Management United Kingdom, 2017, Vol. V. http://ijecm.co.uk/, ISSN 23480386

[5] S. B., Owusu-Mintah, Introduction to Entrepreneurship, Prints \& Cities Publications, Cape Coast, Ghana, 2015.

[6] T., Khanna and K. G., Palepu, Winning in Emerging Markets: A Road Map for Strategy and Execution. Harvard Business Review Press: Boston, MA., 2010.

[7] J., Mairand I., Marti, Entrepreneurship in and around institutional voids: A case study from Bangladesh, 2009, Journal of Business Venturing 24 (2009) 419-435

[8] C., Jerzy, Entrepreneurship and Job Creation. Kozminski University, Warszawa, PolandIn: Management and Economic Policy for Development. Nova Science Publishers, 2014, Inc ISBN: 978-1-63117-606-7

[9] International Trade Centre (ITC), SME Competitiveness in Ghana: Alliances for Action Geneva, 2016, Doc. No. OCE-16-27.E accessed 31 August, 2019.

[10] F. R., David, Strategic management: concepts and cases (13th ed). Francis Marion University Florence, South Carolina Prentice Hall, Pearson, 2011, ISBN 13: 978-0-13-612098-8

[11] H., Mintzbertg, The Strategy Concept II. Another look at why organizations need, Berrett-Koehier Publishers strategies, California, 1987.

[12] P., Kotler, \& K. L., Keller, Principles of Marketing (14th ed.). Pearson Education Limited, Edinburgh Gate, Harlow, Essex CM20 2JE England, 2012.

[13] M. K., Kozan, \& Akdeniz, L., Role of strong versus weak networks in small business growth in an emerging economy. Administrative Sciences 2014. (2076-3387), 4, 35-50. doi:10.3390/Admsci4010035

[14] S., Majumdar, Growth strategy in entrepreneur managed small organizations, A study in auto component manufacturing organizations in central India. South Asian Journal of Management, 2013, 20(4), 31-55.

[15] S. Wendy, "Governmental Organizations and Global Activism: legal and Informal Approaches" 1997

[16] A., Thompson, A., Strickland, \& J., Gamble, Crafting and Executing Strategy: Text and Readings, McGraw - Hill Irwin 15th edition, 2007.

[17] T., T. Racquel A Qualitative Study of the Growth Strategies of Mature Small Businesses. Thesis for Doctor of Business Administration Degree. College of Management and Technology, 2016, ScholarWorks@waldenu.edu.

[18] Bello, B., \& Ivanov, S., Growth strategies for very small organizations: A case study of a very small entrepreneurship. International Journal of Organizational Innovation, 2014, 6(4), 51-53. Retrieved from http://www.ijoi-online.org/

[19] D. I., Prajogo, C. M., Mcdermott, \& M. A., Mcdermott, Innovation orientations and their effects on business performance: Contrasting small- and medium-sized service firms. R\&D Management, 2013, 43, 486-500. doi:10.1111/Radm.12027

[20] H. Mintzberg Electronic Book Managing San. Francisco, Berrett-Koehier Publishers strategies, california management review, fall, 2009. p. 25-31.

[21] T. O., Mgeni, Impact of Entrepreneurial Leadership Style on Business Performance of SMEs in Tanzania. Entrepreneurship and Organizational Management, (2015), 2(1): 1-9. 
[22] H., S., Marieke Ute and V., Sunčica CEO's Values, Management Style and Firm Performance: Evidence from Social Enterprise in Europe, 2015.

[23] OECD, Effective local strategies to boost quality job creation, employment, and participation; Report prepared for the G20 Labour and Employment Ministerial Meeting Melbourne, Australia, 2014, 10-11 September 2014

[24] K. C., Laudon, \& J. P., Laudon, Management Information System: Managing the digital firm (12thed.). Pearson Education, Edinburgh, England, 2003.

[25] O. A., Yaw, Modern Economics for Senior Secondary School Book One. Black Mask Ltd Cantonments, Accra, Ghana, 1996.

[26] S. J., Skripak, Fundamentals of Business. Pamplin College of Business and Virginia Tech Libraries, 2016.

[27] T. C. Obiwuru, A. T. Okwu, V. O., Akpa, \& I. A., Nwankwere, Effects of leadership style on organizational performance: A survey of selected small scale enterprises in Ikosi-Ketu Council Development area of Lagos State, Nigeria. Australian Journal of Business and management Research, 2011, 1(7): 100-111.

[28] Bass B. M., The ethics of transformational leadership, KLSP: Transformational Leadership, Working Papers, 1997.

[29] D. C., Hambrick, Upper echelons theory: An update. Academy of Management Review, 2007, Academy of Management doi: 10.2307/20159303.

[30] K. S., Oladipo, O. Jamilah, S., Abdul daud, L. D. Jeffery and D. K., Salami Review of leadership theories and Organizational performances, International Business Management Journal, 2013, $7(1), 50-54$

[31] P. M. Podsakoff, S. B., MacKenzie, R. H., Moorman and R., Fetter, Transformational leader behaviours and their effects on followers" trust in leader, satisfaction and organizational citizenship behaviours, Leadership Quarterly, 1990, 1, 107-142

[32] A., Abdullah, A., Ismail F. A., Halim, D. N., Munna, A. S Shminan, and A. L., Muda, The mediating effect of empowerment in the relationship between transformational leadership and service quality, J. Bus. Manage., 2009, 4(4), 3-12

[33] T. O. Mgeni, Impact of Entrepreneurial Leadership Style on Business Performance of SMEs in Tanzania. Entrepreneurship and Organizational Management, 2015, 2(1): 1-9.

[34] B. Mohsen \& L., Adala, The Strategic Choices of Small Medium-Sized Enterprises Integration: Evidence from Specific Economic Territory, Acta Universitatis Danubius, 2015, Vol 11, No 2.

[35] J. Hayton, Leadership and Management Skills in SMEs: Measuring Associations with Management Practices and Performance. Business Innovation and Skills Research Paper, 2015, 224: 1-74.

[36] V. Goh Yuan, Sheng \& N. S., Geoffrey, University of Western Australia, The Role Of Ethical Behaviours In The Relations Between Leadership Styles And Job Performance, ANZMAC Conference: Corporate Responsibility Young", NBER Working Paper Series, 2005, August.

[37] M. Franco, \& P. G. Matos, Leadership Styles in SMEs: A Mixed-Method Approach. International Entrepreneurship and Management Journal, 2013, 3: 1-27.

[38] B. P., Uchenwamgbe, Effects of Leadership Style on Organization Performance in Small and Medium Enterprises (SMEs) in Nigeria, European Journal of Business Management, 2013, 5 (23): 53-73 OX1 1BN 
[39] T., Trottier, M. Van Wart and X., Wang, Examining the Nature and Significance of Leadership in Government Organizations, Public Administration Review, 2008, 319-333

[40] A., Ismail, F. A., Halim, D. N., Munna, A., Abdullah, A. S. Shminan and A. L., Muda, The mediating effect of empowerment in the relationship between transformational leadership and service quality, J. Bus. Manage, 2009, 4(4), 3-12.

[41] N., I. Akeke, Factors of Strategic Leadership: Antidote to Firm Performance. International Journal of Management Sciences, 2016, 7(1): 7-13.

[42] R., W. Belk, Extended Self in a Digital World, Journal of consumer Research, University of Chicago Press, 2013, Vol.40, No. 3.

[43] J., K. Adu-Yeboah \& D. Obiri-Yeboah Practical Social Studies for Senior High Schools, Kwadwoan Publishing, Dansoman, Accra, Ghana, 2008.

[44] T., Peter, Reimage, London: DK, 2003.

[45] HEART - Health \& Education Advice and Resource Team Engaging the Private Sector in Skills Development. Oxford Policy Management, United Kingdom. Oxford, 2013. 